\title{
Study on the Cultural Products Based on the Perspective of National Culture Security
}

\author{
Ju He \\ School of Political Science and Public Administration, University of Electronic Science \\ and Technology of China, Chengdu, 611731
}

\begin{abstract}
This article, from the perspective of cultural products, analyzes the role that the manufacture of cultural products plays in safeguarding national culture security, and from a critical perspective investigates the differences in the nature between the elite cultural products and mass cultural products as well as how the mutual transformation of the two affects the national culture security. Meanwhile, through the interpretation of the two production paths-cultural products replication and innovation,this paper also reveals the issues of national culture security involved in the development and utilization of cultural products.
\end{abstract}

Keywords: Cultural products, National culture security, Cultural activity

\section{Introduction}

National cultural security contains a wide spectrum; broadly speaking, all the cultural phenomena related to national culture interests and ideology security are research areas of national culture security. In the context of economic globalization, the traditional ideological strategy has been gradually replaced. Nowadays, the battle inside the culture is actually the battle of the cultural production and values output. In addition, with the market economy generally recognized by all the countries in the world, the survival of any culture needs to go through the testing of the market, which makes the management of cultural industries and the production of cultural products become the key to safeguard national culture security and strength the cultural influence overseas.

\section{National Culture Security and Cultural Products}

National culture security is a concept with strong Chinese cultural characteristics, and there is not a specialized foreign terminology in correspondence with it; while the international academic community discusses on this issue, they tend to use non-traditional security, culture exceptions or cultural diversity etc ${ }^{[1]}$. Thus, it is easy to find out that national culture security is a very complex concept; currently, the mainstream scholars in China divide the definition into the following three categories: firstly, they traditionally view culture as a product of people's mental world, and cultural security is spiritual security of people; the representative views are "national culture security is mainly spiritual wealth safety of a nation, including its ethnic beliefs, cultural traditions, morality, spiritual and cultural heritage and so on"[2]; secondly, the national security is seen as the international relations, its essence lies in 
the contest of different nation's interests, its dominant viewpoint is "for the national sovereignty, the national culture security mainly refers that a country's cultural sovereignty is sacrosanct, a country's cultural traditions and cultural development choices must be respected, including the country's cultural legislative power, the right of cultural management, the options of cultural systems and ideologies, the autonomy of cultural transmission and cultural communication etc" [3]; thirdly, the culture is considered as a tool to maintain social integration, cultural security also relates to social institution security, its representative view is "cultural security is to prevent the national culture from the infiltration and erosion of heterogeneous culture to protect its people's values, behavior, social systems from remodeling and assimilation".Although the three above-mentioned definitions share the differences of alleged object, they all have emphasized the national culture security as an ideological and spiritual world security.

From the relations between the national culture security and the cultural products, it can be seen that the production and circulation of cultural products play a role in protecting and inheriting the national culture and resisting the invasion of the foreign culture to a certain extent. This is because cultural products are the core of cultural industries; the consumption of it can foster the growth of culture elements beneficial to national culture safety; simultaneously, the dissemination and promotion of cultural products are also the key to compete in international world and capture cultural discourse.

\section{The Categories of Cultural Products and National Culture Security}

Cultural products can be divided into following two categories---the elite cultural products and mass cultural products, such as museums and TV. Harold · L - Velen Chomsky considered the distinction between the elite cultural products and mass cultural products lies in that they are produced under the different social contexts ${ }^{[4]}$, the elite cultural products are created under the supervision of cultural elite, the critic standard against it is systematic and it is independent on the consumers of mass cultural products; the mass cultural products are standardized in the way and popularized in the usage.

From the perspective of national culture security, the elite cultural products can effectively establish the social mainstream values in the formation of a demonstration effect and implement it into the various aspects of social and cultural phenomena. The popular culture is the key to defend national cultural identity and maintain social stability. Although there exists digesting and being digested relationship between the two cultures, the internal social values contained should be consistent. In the face of the invasion of foreign cultural products, the elite cultural products can affect the macroscopic flow direction of social consciousness and the products of mass culture and place advantages of uniqueness and nationality against largescale expansion of foreign cultural products.

\subsection{The relationship between elite culture and mass culture}

\subsubsection{Digesting and being digested}

Former head of French Culture Studies department August Girard said: "by a strange bondage, some cultural policy 
builds a huge imbalance in care of democratization. The act of public authority is to provide services for those in the poorest and farest places from the capital......the result is that a public authority's behavior is also conducive to favoring high culture, expanding the national cultural authorities rigidly, and making people themselves lose interest in public facilities"[5]. In the crisis management of this culture, the compulsory of defending national culture identity will grow with the influx of foreign cultural products, and ultimately national culture security will get into a kind of desperation: on the one hand, the culture advocated by the public power is a kind of elite culture, based on which both the production of cultural products and propagation medium are superior in quantity and quality than that of popular culture. Thus, the mass culture is constantly digested by the elite culture, and ultimately unable to participate in the international competition of cultural products. On the other hand, with the influx of foreign cultural products, it will inevitably require their national culture products to be created with comparative advantages; however, the popular culture, being digested by the elite culture, has been unable to provide cultural products with local characteristics.

However, the digestion role of elite culture is not necessary; on the contrary, it is also constrained by the mass culture. Although in need of social stability, the mass culture and elite culture have usually been described as two different orientations of the homologous culture, the differentiation between the two is real and should be noted. Popular culture makes people at all levels share a similar view about culture, politics, belief systems, etc; but the elite, as the actual controller of the economy and politics, will take the initiative to cater for the popular culture in order to achieve social stability. Some scholars have criticized this is the depravation of elite culture; but, the truth is that, with the advancement of industrialization, the elite culture becomes much more readily available, and will eventually be transformed into the popularized cultural products.

\subsubsection{Transforming and being transformed}

Mass cultural products can be transformed into the elite cultural products in certain circumstances, the key lies in the easy availability of cultural products and the loss of mass consumer groups.

For the national cultural security, it should be wary of popular culture products being optimized, because the loss of mass consumer groups inevitably makes it lose its foundation; if a kind of cultural product is becoming less and less attractive to consumers, consumers will start looking for new alternatives, but it is completely uncontrollable whether the values inherent in the former cultural products will affect consumers' choice of products or not. In other words, consumers will make their choices according to their own interests. But, the values conveyed by the elite cultural products are undergoing a long-time test by the whole society; its absence would mean re-work of the control of entire ideology.

\subsection{The production dilemma of mass cultural products and elite cultural products}

From the perspective of national culture security, China's cultural products face the following dilemma:

\subsubsection{The social elite being constantly influenced by western cultural trends.}

Since modern Zhidong Zhang wrote "Encouraging Learning" essay to advocate "learning from the western", 
the Chinese cultural and political elite have dabbled a large number of Western theories under this logic; after the May Fourth Movement, there produced a kind of much more extreme cultural absorption mode ---being completely westernized. After the foundation of New China, the Marxist philosophy became the mainstream of political and cultural trends in China, and under which influence, the traditional cultural ideology in China was gradually declined. As Saussure said, speech systems dominate verbal behavior ${ }^{[7]}$. The westernized way of speaking will inevitably bring the value judgment changes. Of cultural products, the elite will follow the Western aesthetic, literature or science to conduct its creation, while the elite are independent on people in the consumption of cultural products and have the features of criticism outside the system, which makes the cultural products far from the public and lack of vitality.

\subsubsection{Being operated under the principle of the largest market reward}

While the popular cultural products flooding into the market, the most effective way is to pull the elite culture down the altars, which will make it easier for the community to have access to it. This kind of value choice leads to a strange culture phenomenon, that is, the mass cultural products being optimized are gradually seizing the market share of the elite cultural products being popularized. Such as the survival predicament of Chinese art films, being lack of domestic art film theaters, it results in many award-winning dramas in foreign countries can not be screened in China. However, these dramas usually take Chinese mass society as the model and depict the lives of ordinary people in China. While domestic commercial blockbusters are taking the high investment approach to depict stuporous Vanity Fair or social elite's lifestyles, and its box office repeatedly beats the billion mark. Thereby, the popular culture is lack of attention, and the ugly dross of the elite culture is to be enlarged in the form of appreciating the ugliness.

\subsubsection{The influence of foreign culture on the national cultural production}

Foreign cultural products can be widely disseminated in China, because their own production must be sophisticated, and for a very long time,the foreign cultural products are refracted by a social elite values, which makes the foreign cultural products equipped with moral character of elite culture both in production and on the connotation. As for the country's two cultural levels, the reason why foreign cultural products are able to achieve good economic and social reputation is mainly because the country's elite cultural products are uncompetitive in terms of quality, and the mass cultural products can not meet the pursuit of psychological demands of following the international trends.

\section{The Creation of Cultural Products and National Culture Security}

There are two paths for cultural production, one is to make certain cultural resources as the blueprint for large-scale standardized replication; another is to create new cultural products according to the characteristics of Chinese own cultural resources. For national culture security, the two kinds of production paths have defended the cultural values of the nation, but the difference between the two is that the former stressed the intrinsic value of cultural resources by repetition, while the latter strengthened the temporal adaptation of cultural resources by 
fostering. In contrast, the latter is a way of advancing and dynamic production but the former is a way of static culture retention. In the context of globalization, only the cultural products with innovation can protect the safety of their own culture while outputting values externally.

\subsection{Duplication of the industrial age of culture}

Creative cultural industry, since its birth, has been caught in the debate of "creating the culture, or copying the culture". When the creative cultural industry is also known as the "culture industry", Adorno and Horkheimer said: culture industry is the workplace for serialization, standardization and division of work ${ }^{[8]}$. The value transformation of cultural practices removed its criticism function. Thus, Adorno and Horkheimer worried the culture became a victim of industrial mass production, and standardized production obliterated the personality of the culture, which forever stripped the culture of its uniqueness and artistic vitality and eventually made it become a fragile commodity. Although Adorno and Horkheimer's views were too radical, it still reflects the natural mode of production and nurture of the contemporary cultural products in China. This mode of production makes the cultural products be bound in the technology mimics, and the products made in this way are not only unattractive, but also to some extent, compresses and distorts culture connotations.

From the perspective of national culture security, mass production of mechanical culture reproductions will lead to two consequences, as shown in the following chart:

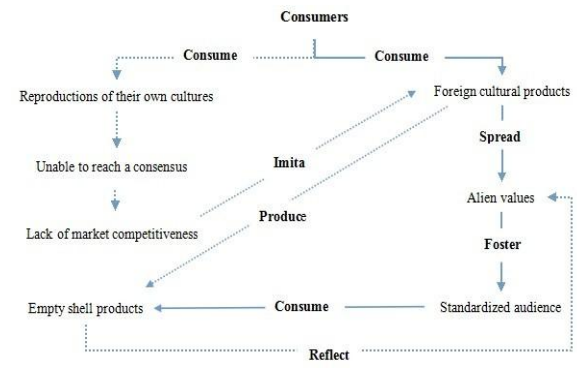

Fig. 1: Two consequences of mechanical culture reproductions

It can be found out from the above chart that on the one hand, consumers can not get emotional resonance from their own cultural products. Instead, they turn to pursue the foreign cultural products in line with the trend, which can ultimately lead the foreign cultural products begin to breed the standardized audiences seeking foreign cultural values. On the other hand, domestic cultural products are unattractive and out of the market. The manufacturers of domestic cultural products will certainly begin a new round of imitation in pursuit of economic interests after seeing the excellent performance of the foreign cultural products. Thence, such kind of culture reproductions floods into the market. The standardized audiences accurately receive this specific value under the similar shape.

\subsection{The innovation of the cultural industry era}

With the development of mass culture, the radical concept "culture industry" is gradually being replaced by "creative cultural industry" and the essential difference between the two lies in the integration of innovation. In 1975, a multidisciplinary research team in France started to analyze the cultural products and services, they believe that "creative cultural industry" is a holistic concept, and its mode of operation is very colorful. Its colorfulness exists in the form of work organization, the composition features of 
the product itself and the content, a variety of institutionalized forms of cultural industry, and even the attributes and status of the products targeted by consumers $^{[9]}$. Wherefore, scholars gradually sort out the distinction in the nature between "cultural industry" and "creative cultural industry".

From the perspective of cultural production, Malcolm Waters assumes that simple and mechanical replication has been unable to meet the needs of global flows of the culture, but the creative cultural industry integrated with innovation allows all kinds of ideas, information, obligations, values and taste for continuous communication, such circulation of cultural products will be achieved through individual, symbols and electronic simulation ${ }^{[10]}$. The integration of innovation marks a leap for the cultural industry from the material industry to the spiritual industry and the cultural products has gradually evolved into a signifier system with particular values. In 2007, "the economic performance of the UK's creative industries", published by the British Culture, Media and Sport department, explicitly defined the creative cultural industry as the innovative industries, and specified the creation of ideas, picture, symbol, design, creativity and culture belonging to this category ${ }^{[11]}$.Accordingly, the cultural products in the Western developed countries have been developed to a much more advanced mode, as the following chart shows:

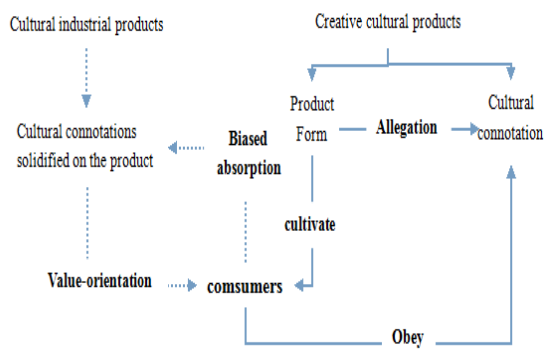

Fig. 2: The differences between creative cultural products and cultural industrial products

It can be found out from the above chart that cultural product, as a symbol, is something out of itself. In such a case, there is no doubt that cultural products will be able to achieve the ever-changing of the appearance but nothing to distortion in the innovation, because the inherent value system has been printed in the cultural meaning systems. From the perspective of dualistic, it does good to cultural products and cultural connotation to strip the intrinsic cultural value system of the shackles of cultural products innovation and give the power of value judgment back to the consumer. Consumers achieve the spiritual satisfaction through the symbolic systems between cultural products and cultural connotation. Thus, the final mission of cultural products lies not in the orientation of value, but has fostered the standardized audiences with semiotic quality. Only by internalizing the culture in the symbolic system of people's spiritual world, can the implementation of cultural security be targeted.

\section{Conclusion}

The intrinsic economic attributes of cultural products make it a cross context in the national economic security and national culture security. The production and sales of cultural products do not necessarily play its role in consolidating national culture security. However, each 
aspect, from production to distribution of cultural products, runs through defense of the dignity of the national culture, transmission of the ideology, building the value system and other national cultural security essence.

There exists the possibility of mutual transformation between the elite culture and mass culture products. However, such kind of transformation may exist in two deviations: one is the elite cultural products being popularized; it would involve in the deformation of aesthetic or literary tradition under the supervision of the elite in the whole society. The elite cultural products will deliberately digest their complexness and rationality, and even be presented in a vulgar and simple way in order to meet the public. For national culture security, this could mean the loss of a cultural benchmark. Another is mass culture products being optimized, involving in the decreation of consumer groups. Social elites begin to protect it in a way as the elite cultural products do in order to maintain such a kind of culture not to disappear, and the social value system originally attached to the mass culture products will gradually be forgotten by people as its public nature disappears.

The two paths of cultural products actually reflect two attitudes towards culture, that's static retainment or dynamic production. Although the two modes of production both have a positive effect on the national culture security, dynamic production from the point of view of history and space dimensions enables the culture to renew its connotation and denotation in the evolution of the history, and adapt to the rapid social change in the current environment to keep vitality. The dynamic production actually embodies the national cultural security strategy combined with both defense and attack, which means to spare no effort for the excavation, conservation and heritage of the outstanding traditional culture and for the continuing spread and promotion of the nation's outstanding cultural products.

\section{References}

[1] Yuanmeng Tang, "Comprehensive Studies on National Culture Security"[J], Journal of Guangxi Social Science, 2012 (12).

[2] Jia $\mathrm{Xu}$, "The Redefining of International Economic and National Culture Safety"[J], Journal of PLA University of Foreign Languages, 1998 (6).

[3] Huilin $\mathrm{Hu}$, "Development of Cultural Industry and National Culture Security"[M], Guangdong People's Publishing House, pp:106, 2005.

[4] Harold· L. Velen Chomsky, "Mass Society and Mass Culture: Independent or Interdependent?'[J], American Journal of Sociology, American Journal of Community Psychology,1946 Edition, Volume 29.

[5] August Girard, "Cultural Industries : Obstacles or New Opportunities to Cultural Development?"[M], the UNESCO in 1982.

[6] Qi He \& Zhidong Zhang, "Encouraging Learnin' the Extension of Encouraging Learning"'[M], Hubei People's Press, 2002.

[7] F.de Saussure, "Course in General Linguistics" $[\mathrm{M}]$, Foreign Language Teaching and Research Press, 2001.

[8] Adorno and Horkheimer, "Industrial Products of Cultural Consumption Data”[J], 1974.

[9] Migne, "Capitalization of the Culture"[M], 1980.

[10] Waters, "Globalization" $[\mathrm{M}]$, London Routledge 1995.

[11] "The Economic Performance of the UK. A Creative Industries"[Z], London: Department of Culture, Media \& Sport 2007. 